\title{
Statistical analysis of MAIB database for the period 1990-2016
}

\author{
B. Navas de Maya, S.I. Ahn \& R.E. Kurt \\ Department of Naval Architecture, Ocean \& Marine Engineering, University of Strathclyde, Glasgow, UK
}

\begin{abstract}
Maritime transport has been threatened by ship accidents since its origins; hence, a safety increase is a decisive requirement within the maritime sector. Aiming to improve aforementioned safety, this paper performs systematic statistical analysis of ship accidents for the majority of vessel categories. Moreover, the data for this study is provided by the Marine Accident Investigation Branch (MAIB), which includes 38974 entries regarding maritime accidents between 1990 and 2016. Numerous past studies have emphasized the importance of accident statistics in risk quantification, as statistical analysis may demonstrate the trends for certain accidents. Hence, this paper first applies descriptive statistics in order to have a comprehensive overview of the database. Then, this paper perform some hypothesis tests to investigate the relations among some variables (e.g. the vessel category and the accident outcome or the vessel age and the loss of the vessel).
\end{abstract}

\section{INTRODUCTION}

Accident analysis within the past decades reveals that shipping accidents have always been a concern for the maritime sector (Eliopoulou et al., 2016). As 90\% of world trading is still carried out by the maritime sector (Chauvin et al., 2013), the shipping industry is always looking for implementing new safety measures to reduce accident rates. However, it is a challenging task to find the root causes that led into an specific accident, since accidents are the result of a complex chain of events, where normally there is more than one factor solely responsible for the accident (Kristiansen 2013).

By analyzing the literature, it is possible to find numerous authors that identify human factors as the main agent involved into past accidents. Thus, humans have been found responsible for accidents not only in the maritime sector (Turan et al., 2016, Navas de Maya et al., 2018) but also in some strategic sectors like nuclear or aviation (O'Hare et al., 1994, Azadeh \& Zarrin 2016).

With the purpose to give a better insight into past maritime accidents, this paper is organized as follows: After a generic introduction to maritime accidents, its main causes and how these accidents affect overall maritime safety, the authors present the historical accident data that is analyzed in this paper. Moreover, the methodology is explained, and two different sets of statistical analysis are performed. The first set describes the historical database (e.g. ship specifications or accident location) by applying descriptive analysis. The second set of statistical analysis aims to investigate the relation between various variables from the database (e.g. the ship type and the accident outcome). In addition, identified relations amongst variables are further commented and explained.

\section{HISTORICAL ACCIDENT DATA ORIGIN}

The historical accident data that was analyzed within the scope of this study was obtained from the Marine Accident Investigation Branch (MAIB). MAIB has recently implemented the European Marine Casualty Information Platform (EMCIP) nomenclature. Hence, the generic ship types analyzed within this study are named by following aforementioned nomenclature (i.e. cargo ships, fishing vessels, fixed offshore drilling units, inland waterway vessels, navy vessels, passenger ships, recreational crafts, and service ships).

Moreover, the analysis of historical accident data was performed for the period 1990-2016, including information about 24757 accidents. For the purpose of this study, an accident was defined as "an undesirable event that results in damage to humans, assets and/or the environment" (Kristiansen 2013). Thus, MAIB database was filtered to include only concept accidents (e.g. grounding or collision accidents). Therefore, incidents are not addressed on this paper, as it only covers accidents involving UK vessels worldwide and all vessels operating in UK 
territorial waters. In addition, a snapshot of the geographic accident location that comprises this study is shown in Figure 1.

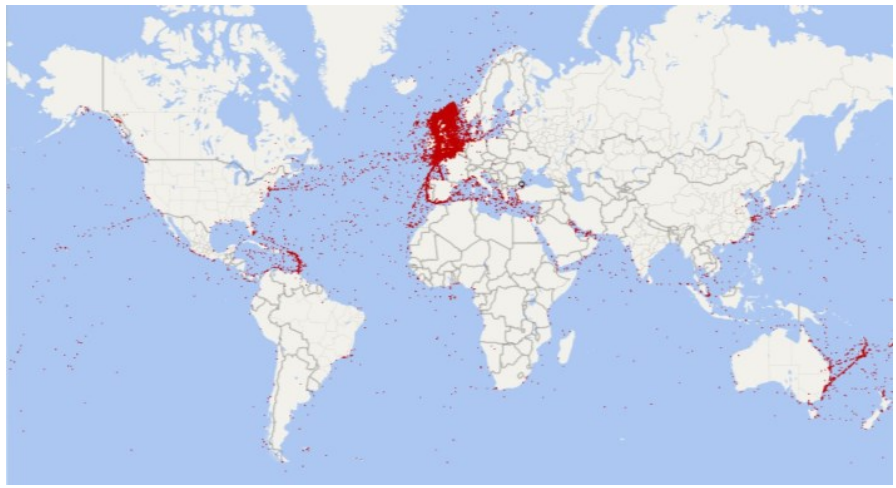

Figure 1. Geographic accident location. Period 1990-2016.

The difference between the total number of entries within the database (38974) and the accidents analyzed within this paper (24757) is caused by two main factors. First, the well-known problem of under reporting, which currently exists in accident investigation. Therefore, there was a lack of collected information affecting many entries in the database. Second, due to current MAIB database structure it is only possible to appoint one underlying factor as responsible for each accident.

Hence, if more factors are found responsible during the accident investigation (e.g. environmental factors or human factors), it is necessary to introduce a new entry in the database for each factor involved (i.e. if there are six factors responsible for an accident, the database will contain six entries for the same ID event). Thus, MAIB structure duplicates the data and increases the complexity of the process when running accident comparisons and statistical analysis if the data is not filtered correctly. Therefore, the original database had to be filtered to cope with aforementioned MAIB structure issues.

\section{METHODOLOGY}

The analysis conducted within this paper start with a set of descriptive analysis, which overall aim to give a better understanding of MAIB database. First, accidents are analyzed according to ship specifications (i.e. type, size and vessel age); accident consequences (i.e. accident outcome, level of ship damage, and number of fatalities and injuries); accident location; and environmental conditions (i.e. sea state, visibility and wind force).

Second, a set of hypothesis tests are performed by using SPSS software. The aim of these tests is to stablish if there is an existing relation amongst various pairs of variables (i.e. the ship type and the accident outcome, the vessel age and the loss of the vessel, and the ship type and the number of fatalities).
In addition, identified relations amongst previous variables are further commented and explained.

\section{STATISTICAL ANALYSIS}

\subsection{Descriptive results}

The distribution of accidents per ship type is given in Table 1; according with MAIB accident database, fishing vessel is the ship type with the highest number of accident recorded (42.46\%), along with cargo ships $(22.55 \%)$ and passenger ships (10.64\%). These results are in line with a similar study, for the period 1990-2012, where general cargo, bulk carriers, passenger ro-ro cargo and fishing vessels were identified as the vessel categories with more serious accidents registered (Papanikolaou et al., 2014).

Table 1. Number of accidents per ship type. Period 1990-2016.

\begin{tabular}{lll}
\hline Ship Type & Number & Distribution (\%) \\
\hline Fishing vessel & 10511 & $42.46 \%$ \\
Cargo ship & 5583 & $22.55 \%$ \\
Passenger ship & 2635 & $10.64 \%$ \\
Recreational craft & 2625 & $10.60 \%$ \\
Service ship & 2607 & $10.53 \%$ \\
Inland waterway & 646 & $2.61 \%$ \\
vessel & 127 & $0.51 \%$ \\
$\begin{array}{l}\text { Navy ship } \\
\text { Fixed offshore } \\
\text { drilling units }\end{array}$ & 23 & $0.09 \%$ \\
Total & $\mathbf{2 4 7 5 7}$ & $\mathbf{1 0 0 \%}$ \\
\hline
\end{tabular}

MAIB database includes a variety of vessel sizes. In order to provide a better understanding regarding which vessels are more prone to cause accidents, Figure 2 captures the number of accidents by vessel size.

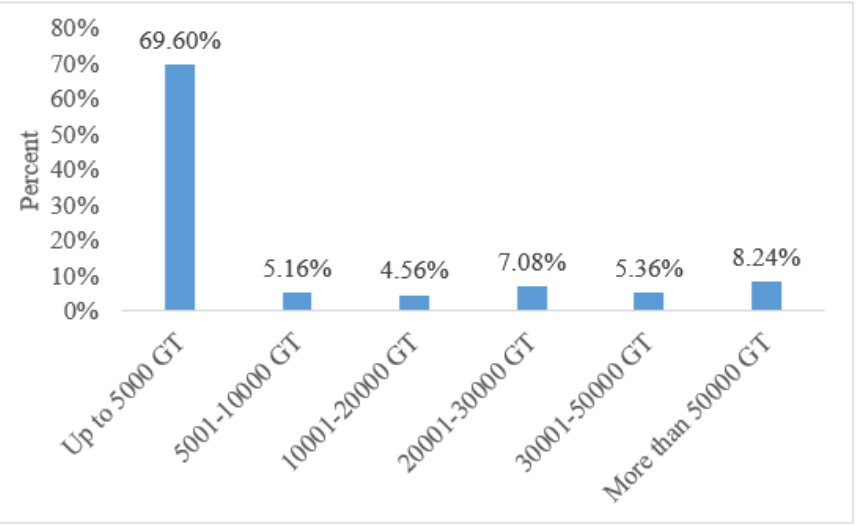

Figure 2. Percentage of accidents per vessel size. Period 19902016.

Figure 2 shows that almost a $70 \%$ of the accidents are caused by small vessels (up to $5000 \mathrm{GT}$ ), while the rest of the accidents are similarly distributed amongst the rest of categories (although a slightly higher 
distribution is found on vessels between 20001-30000 GT and vessels over 50000 GT).

In order to compare if older ships are more likely to have an accident, Figure 3 shows the relation between the total number of accidents and the vessel age. MAIB database has no information regarding the vessel age, hence, this information was established as the difference between the year of build and the casualty date (both provided by MAIB). It is possible to observe from Figure 3 that there is a steady accident distribution for vessels under 20 years.

However, for vessels above 20 years, the number of accidents almost triplicates the previous periods. Similar results were found in a study regarding maritime accidents under Greek flag, over 1000 GT for the period 1974-2010. Aforementioned study identified that vessels over 20 years are the most vulnerable to accidents, with a distribution of $35.66 \%$ (Frangos 2015).

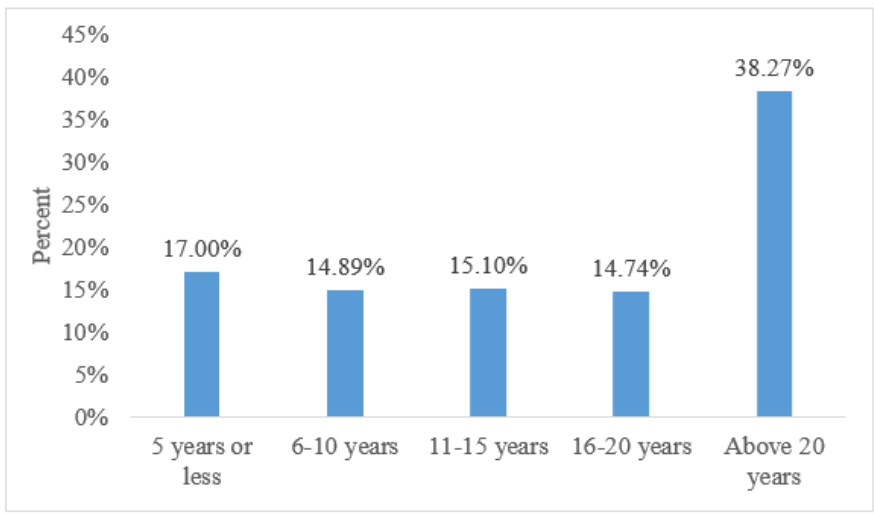

Figure 3. Percentage of accidents per vessel age. Period 19902016.

Regarding the accident consequences, Figure 4 shows the accident outcome distribution.

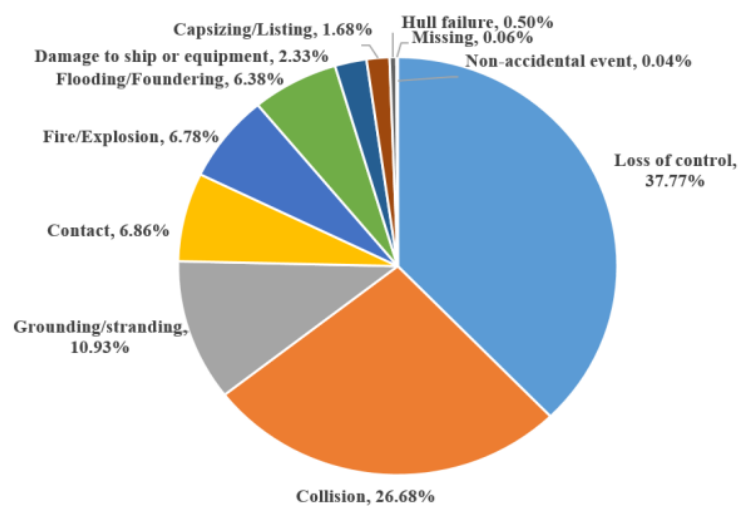

Figure 4. Number of accidents per accident outcome. Period 1990-2016.

It can be observed that a loss of control was reported as the most common outcome (37.77\%), followed by collision $(26.68 \%)$ and grounding/stranding $(10.93 \%)$.
When analyzing the vessel consequences, Figure 5 indicates that the vessel results into damage in almost $80 \%$ of the cases. However, more insight into the kind of damage is not provided. In addition, in $15.96 \%$ of the cases there is a total loss. As a total loss of the vessel is the worst possible outcome, Table 2 provides further details regarding which vessel categories are more prone to suffer a total loss. It is possible to observe that these categories are fishing vessel $(72.16 \%)$ and recreational crafts $(22.24 \%)$.

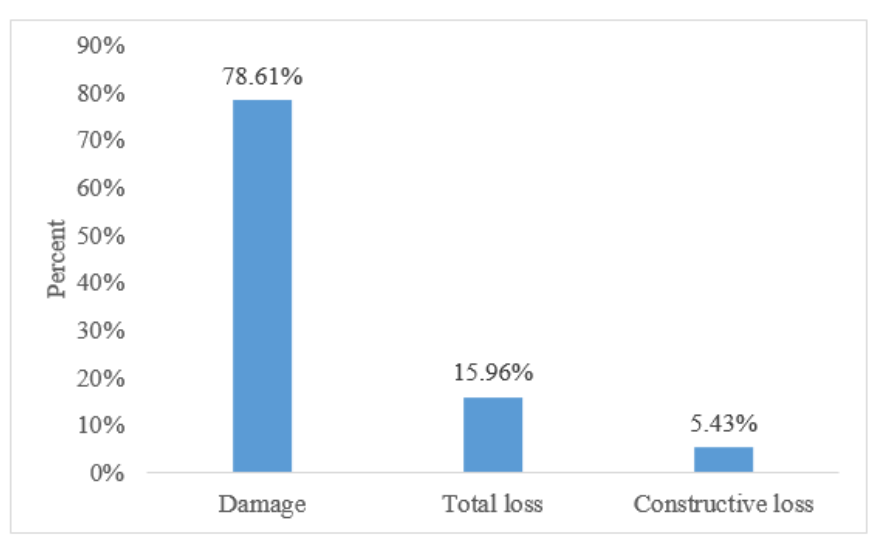

Figure 5. Percentage of accidents per ship damage. Period 19902016.

Table 2. Number of total losses per ship type. Period 1990-2016.

\begin{tabular}{lll} 
Ship Type & Number & Distribution (\%) \\
\hline Fishing vessel & 477 & $72.16 \%$ \\
Recreational craft & 147 & $22.24 \%$ \\
Service ship & 14 & $2.12 \%$ \\
Cargo ship & 12 & $1.82 \%$ \\
Passenger ship & 5 & $0.76 \%$ \\
Inland waterway vessel & 4 & $0.61 \%$ \\
Fixed offshore drilling units & 2 & $0.30 \%$ \\
Total & $\mathbf{6 6 1}$ & $\mathbf{1 0 0 \%}$ \\
\hline
\end{tabular}

Table 3. Number of injuries and fatalities per ship type. Period 1990-2016.

\begin{tabular}{lll}
\hline Ship Type & $\begin{array}{l}\text { No of } \\
\text { Fatalities }\end{array}$ & $\begin{array}{l}\text { No of } \\
\text { Injuries }\end{array}$ \\
\hline Recreational craft & 408 & 818 \\
Fishing vessel & 375 & 1890 \\
Cargo ship & 190 & 1999 \\
Service ship & 70 & 2582 \\
Passenger ship & 60 & 6842 \\
Inland waterway vessel & 9 & 338 \\
Navy ship & 1 & 26 \\
Fixed offshore drilling & & \\
units & 1 & 2 \\
Total & $\mathbf{1 1 1 4}$ & $\mathbf{1 4 4 9 7}$ \\
\hline
\end{tabular}

The last accident consequence that is addressed in this paper is the loss of lives. Table 3 indicates the total number of injuries and fatalities per ship type. It is shown that relatively small vessels (i.e. recreational crafts and fishing vessels) have the highest number of 
fatalities. However, regarding number of injuries, the highest distribution corresponds to passenger ships.

Regarding accident location, it is possible to observe from Figure 6 that a majority of the accidents take place into internal waters, which are defined as the waters inside the inner limit of the territorial sea. In addition, Figure 7 gives a further insight into the accident location, showing that the port area is the most prone for an accident development.

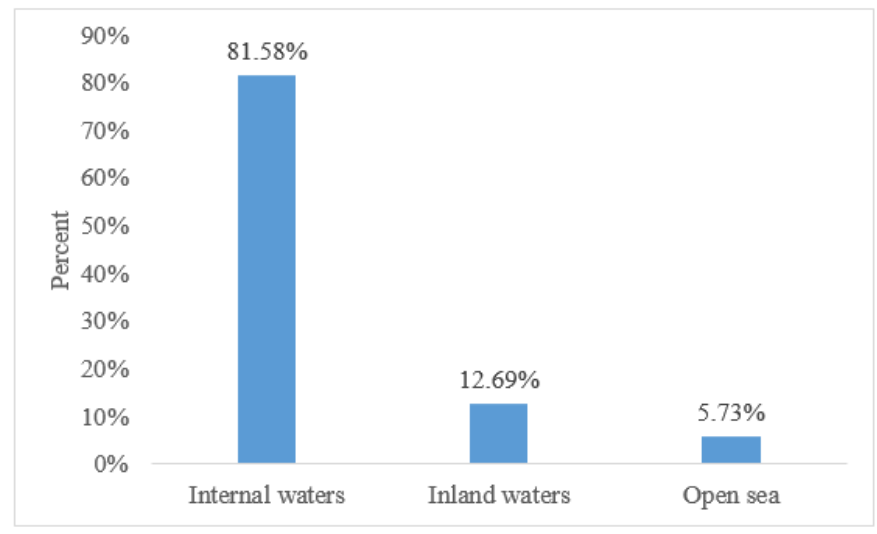

Figure 6. Accident location. Period 1990-2016.

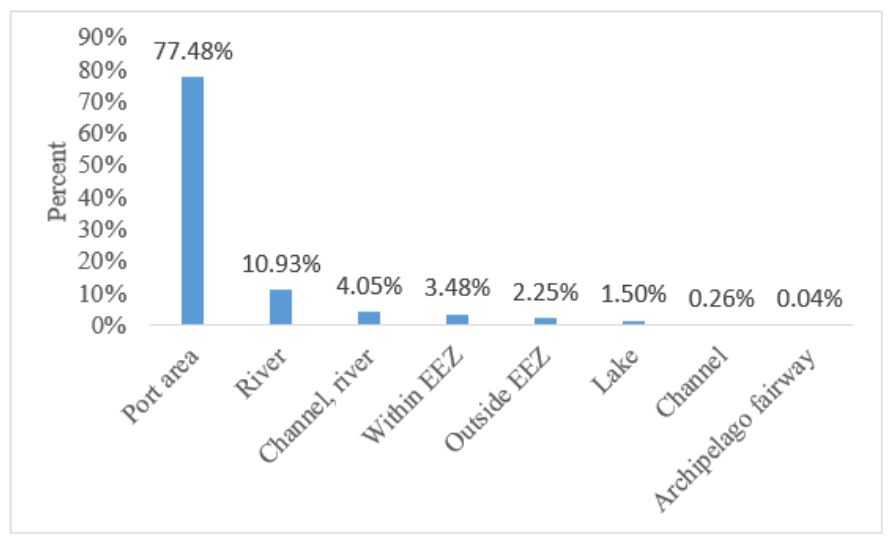

Figure 7. More detailed accident location. Period 1990-2016.

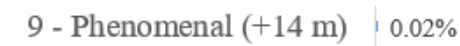

$$
\begin{aligned}
& 8 \text { - Very High }(9.0-14.0 \mathrm{~m}) \quad, 0.05 \% \\
& \begin{array}{l|l}
7 \text { - High }(6.0-9.0 \mathrm{~m}) \quad 0.08 \% \\
\hline
\end{array} \\
& 6 \text { - Very rough }(4.0-6.0 \mathrm{~m}) \quad 0.26 \% \\
& 5 \text { - Rough }(2.5-4 \mathrm{~m}) \quad 8.83 \% \\
& 4 \text { - Moderate }(1.25-2.5 \mathrm{~m}) \quad 25.82 \% \\
& 3 \text { - Slight }(0.5-1.25 \mathrm{~m})-5.88 \% \\
& 2 \text { - Smooth }(0.1-0.5 \mathrm{~m})=53.54 \% \\
& 1 \text { - Calm rippled }(0-0.1 \mathrm{~m})=3.59 \% \\
& 0 \text { - Calm glassy }(0 \mathrm{~m})=1.91 \% \\
& \begin{array}{c}
20 \% \quad 40 \% \\
\text { Percent }
\end{array}
\end{aligned}
$$

Figure 8. Accident distribution by sea state. Period 1990-2016.

In order to conclude with the descriptive section, some analyses are presented below regarding the environmental conditions measured during past accidents. Thus, Figure 8 provides information about the sea state condition. It is shown that half of the accidents (53.54\%) took place during relatively calm conditions, while a quarter of the accidents $(25.82 \%)$ occurred within a moderate sea state.

Regarding visibility conditions, Figure 9 shows that the majority of the accidents occurred with good visibility $(80.67 \%)$, or moderate visibility $(11.80 \%)$.

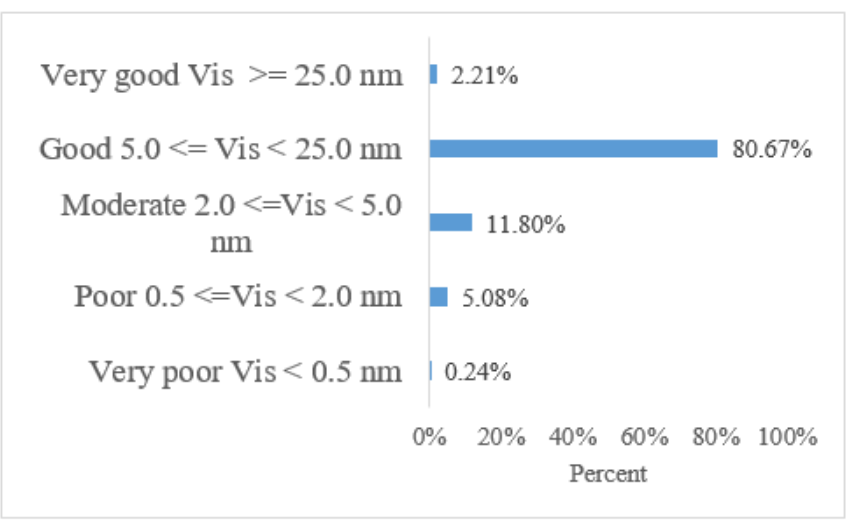

Figure 9. Accident distribution by visibility. Period 1990-2016.

Finally, Figure 10 provides information regarding the wind force. The majority of the accidents took place during moderate conditions (below Force 5 in Beaufort scale), while almost half of the accidents occurred with relatively calm conditions (below Force 2 in Beaufort scale).

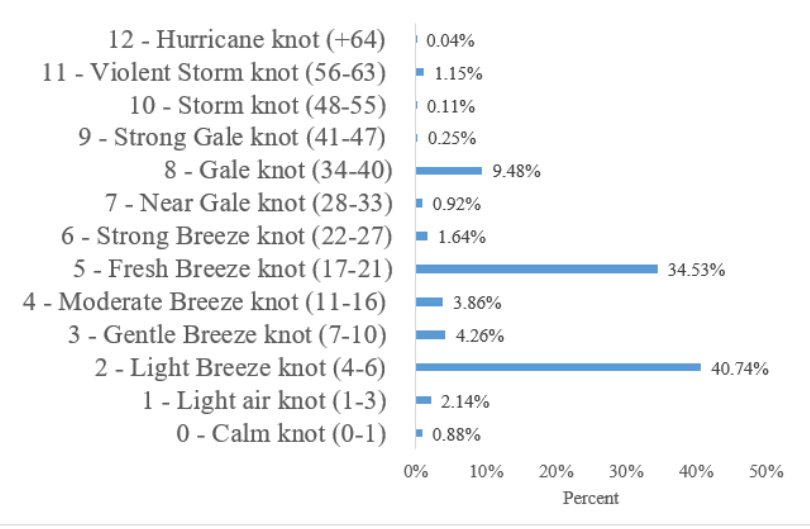

Figure 10. Accident distribution by wind force. Period 19902016.

\subsection{Hypothesis tests of previous results}

The aim of this section is to investigate if there is a relation between various variables from the database by establishing a set of hypothesis tests. This paper will test the null hypothesis that: 1) the ship type and the accident outcome are not related, 2) the vessel age and the loss of the vessel are not related, and 3) the ship type and the number of fatalities are not related.

Aforementioned hypothesis tests are performed by the Pearson chi-square test and the crosstab command in SPSS. In addition, identified relations amongst variables are further commented and explained by 
means of a symmetric correspondence analysis (when this analysis is applicable).

The results for the null hypothesis between the ship type and the accident outcome are shown in Table 4. By looking at the Pearson chi-square index below $(p=0.00<0.05)$, it is observed that the null hypothesis is rejected, which indicates that the variables of ship type and accident outcome are related. Pearson chi-square test shows if there is a relation amongst two variables, however, this test is not able to provide additional information about the strength of aforementioned relation. Hence, in order to investigate this relation in more detail, a symmetric correspondence analysis was performed and results were shared in Figure 11.

Table 4. Results from Chi-Square Test between ship type and accident outcome.

\begin{tabular}{llll}
\hline & Value & df & $\begin{array}{l}\text { Asymptotic } \\
\text { Significance (2- } \\
\text { sided) }\end{array}$ \\
\hline $\begin{array}{l}\text { Pearson } \\
\text { Chi- }\end{array}$ & & \\
$\begin{array}{l}\text { Square } \\
\text { Likelihood } \\
\text { Ratio }\end{array}$ & $6720.423^{\mathrm{a}}$ & 70 & .000 \\
$\begin{array}{l}\text { N of Valid } \\
\text { Cases }\end{array}$ & 6699.335 & 70 & .000 \\
\hline $\begin{array}{l}\text { a. 26 cells (29.5\%) have expected count less than 5. The } \\
\text { minimum expected count is .01. }\end{array}$ \\
\hline
\end{tabular}

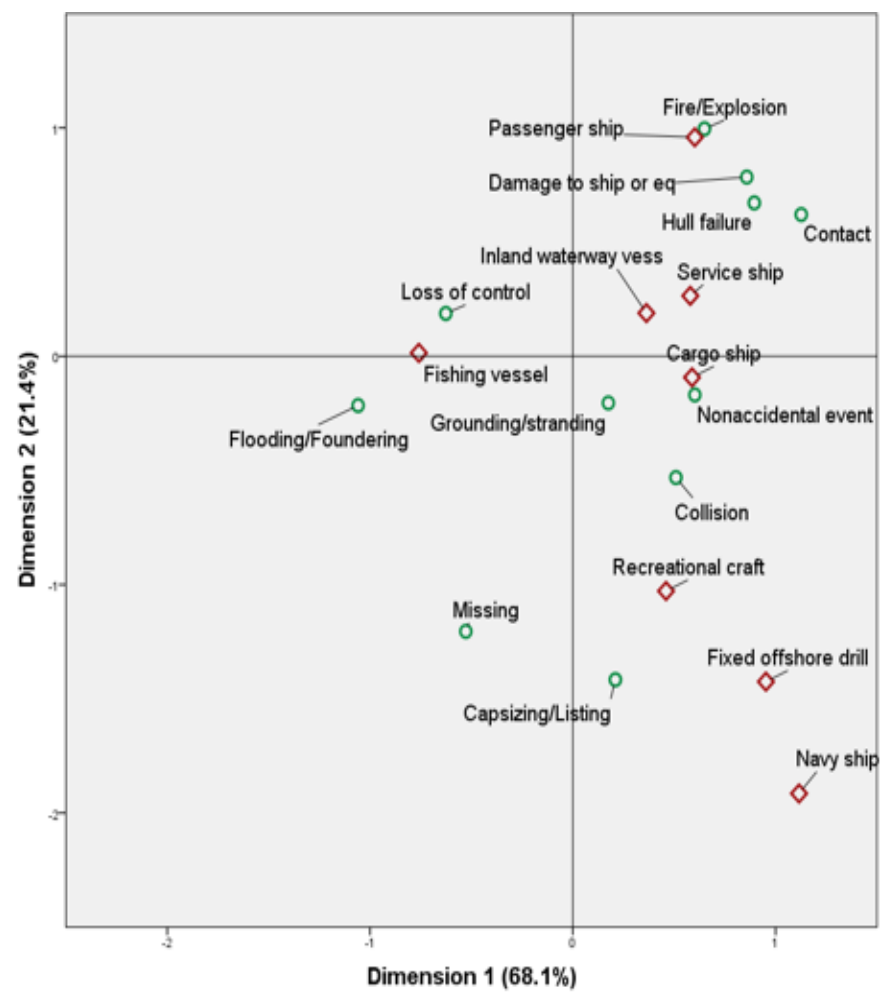

Figure 11. Symmetric correspondence analysis between ship type and accident outcome.

Before proceeding with a further interpretation of the result, it is important to understand that a correspondence analysis provides information about the relativity correspondence that exists amongst two variables (e.g. ship type and accident outcome). Thus, meaningful result could be extracted from the graph by the following principles: 1) proximity between ship types indicates that there is a similarity between two variables. 2) Proximity between accident outcomes indicates that there is also a similarity amongst two variables. 3) If the value for the angle produced when drawing a line from the origin to a ship type and an accident outcome is small, it indicates that those two variables are likely to be associated. In addition, if aforementioned angle is wide, there is no relation (or the existing relation is weak) amongst that those variables. 4) There is a relation between the variables distance from the origin and their association. Hence, points that are close to the origin show a weak association, while further points are strongly related. 5) Finally, there is a relation between the variables distance from the origin and how discriminate they are. Thus, closer points to the origin are less discriminate and vice versa.

In addition, there is a need to assess how much variance the symmetric correspondence test explains within the scope of this analysis, since more variance means that fewer insights into the analysis will be missed. Therefore, it is possible to see from Figure 11 that there is in total a $89.5 \%$ variance for the analyzed data $(68.1 \%$ for the $\mathrm{x}$-axis and $21.4 \%$ for the $\mathrm{y}$-axis).

By analyzing the results displayed on Figure 11, this study found that the accident outcomes "Fire/explosion", "Damage to ship or equipment", "Hull failure" and "Contact" present similarities due to their proximity on the correspondence analysis graph. In addition, regarding the ship type, "Navy ships" and "Fixed offshore drilling units" are represented far apart from the rest of ship types, which indicates that they are disconnected from the others ship types. Moreover, this analysis shows that there is an strong relation between "Fire/explosion" on "Passenger ships" since both variables are far from the origin and the existing angle between the origin and these variables is small, which is a sign of a strong relation (as explained above). Furthermore, "Passenger ships" are also related to "Damage to ship or equipment", "Hull failure" and "Contact". However, as the distance between aforementioned variables and "Passenger ships" increase, it becomes more difficult to justify that a relation exist (due to aforementioned increase regarding the originvariables angle). Additionally, it is observed a small relation amongst "Fishing vessels" and the accident outcomes "Flooding/Foundering" and "Loss of control".

Following with the hypothesis tests, in order to determinate if older vessels are more prone to suffer from a total loss when an accident occurs, a test was also performed amongst the variables vessel age and ship damage. Results from Table 5 show that the null 
hypothesis is rejected $(\mathrm{p}=0.00<0.05)$, which indicates that both variables are related.

Table 5. Results from Chi-Square Test between vessel age and ship damage.

\begin{tabular}{llll}
\hline & Value & df & $\begin{array}{l}\text { Asymptotic } \\
\text { Significance (2- } \\
\text { sided) }\end{array}$ \\
\hline $\begin{array}{l}\text { Pearson } \\
\begin{array}{l}\text { Chi-Square } \\
\text { Likelihood } \\
\text { Ratio }\end{array}\end{array}$ & $3013.201^{\mathrm{a}}$ & 10 & .000 \\
$\begin{array}{l}\text { N of Valid } \\
\text { Cases }\end{array}$ & 860.0119 & 10 & .000 \\
\hline $\begin{array}{l}\text { a. } 11 \text { cells }(61.1 \%) \text { have expected count less than 5. The } \\
\text { minimum expected count is .02. }\end{array}$ \\
\hline
\end{tabular}

Finally, a last hypothesis tests was performed to investigate if there is a relation between the ship type and the number of fatalities. As shown in Table 6, the null hypothesis is rejected $(\mathrm{p}=0.00<0.05)$, which means that different ship types are more likely to have accidents where fatal consequences are involved

Table 6. Results from Chi-Square Test between ship type and number of fatalities.

\begin{tabular}{llll}
\hline & Value & df & $\begin{array}{l}\text { Asymptotic } \\
\text { Significance (2- } \\
\text { sided) }\end{array}$ \\
\hline $\begin{array}{l}\text { Pearson } \\
\begin{array}{l}\text { Chi-Square } \\
\text { Likelihood } \\
\text { Ratio }\end{array}\end{array}$ & $1048.052^{\mathrm{a}}$ & 90 & .000 \\
$\begin{array}{l}\text { N of Valid } \\
\text { Cases }\end{array}$ & 725.547 & 90 & .000 \\
\hline $\begin{array}{l}\text { a. } 86 \text { cells }(78.2 \%) \text { have expected count less than 5. The } \\
\text { minimum expected count is .00. }\end{array}$ \\
\hline
\end{tabular}

\section{CONCLUSIONS}

In this paper, a set of statistical analysis were performed over data regarding 24757 accidents. Information about aforementioned accidents was obtain from MAIB database for the period 19902016, including all accidents involving UK vessels worldwide and all vessels operating in UK territorial waters.

The aim of this paper was to show the current distribution of maritime accidents, in order to provide a better understanding of accidents as complex processes. To complete this aim, two sets of analysis were performed, and the most representative trends were shared in this paper. The first set of analysis described the historical database (e.g ship specifications or accident location) by means of descriptive analysis, while the second set investigated the relation between various variables from the database by means of hypothesis tests.

Regarding the descriptive analysis, according to our analysis, fishing vessel, cargo ships and passenger ships are the vessel types with the highest number of accident recorded. These findings are in line with expected results, as fishing vessels are normally operating in hazard environments, with the consequences that these operations might imply (i.e. damage to equipment or loss of ship). The main reason for cargo vessels to present a high number of accidents is the fact that MAIB accident database also includes accidents that occurred during port operations (i.e. loading/unloading, which are critical operations and they involve a high risk to develop an accident). Furthermore, passenger vessels are more prone to suffer an accident than other vessel categories due to the frequency they go to port (i.e. collision or loss of control on port when loading/unloading passengers).

In addition, further analysis revealed that small vessels (up to 5000 GT) are more likely to suffer an accident. These results are expected since fishing vessels and recreational crafts are responsible for a high percentage of the accidents, and they are generally the smallest vessel categories. Moreover, a comparison between vessel age and ship damage was performed. As it was expected, older vessels are more likely to be totally lost after an accident. These vessels normally do not have a state of the art technology (since it is not profitable for the owner to invest after a certain vessel age) or they do not comply with the latest non-mandatory safety measures. Hence, in the event of an accident, older vessels have fewer chances to survive the accident outcome.

Regarding the loss of lives and the number of injuries, it was observed a higher number of fatalities on fishing vessels and recreational crafts, which was expected due to these vessels' size and operational conditions (as explained before). Nevertheless, the highest number of injured people were located on passenger vessels. These vessels are in general safer, however, due to the high number of passenger (who are generally not familiarize with the vessel operating conditions) that they transport in a daily basis, it is possible to assume that there will be more accidents than in other vessels, which just operate with an experienced crew.

Concluding with the descriptive analysis, a last set of analysis were performed to study the relation between environmental conditions and the possibility to have an accident. Surprisingly, the majority of the accidents took place during good weather conditions (i.e. good visibility, wind and sea state). However, these results might be explained due to two main reasons. First, ships will not generally operated within extreme environmental conditions. Second, during good weather conditions, crewmembers stay less alert to their surroundings and they are more likely to rely on equipment. Therefore, if there is a technical failure or an obstacle on the vessel's course, it will be possibly not identified on time, with the consequent accident development. 
Regarding the hypothesis tests, overall it was observed that there is a relation amongst the variables ship type and accident outcome, vessel age and total loss of the vessel, and vessel type and number of fatalities. However, due to the differences within the data format (i.e. comparison between nominal and ordinal variables on SPSS software), it was only possible to perform a symmetric correspondence analysis for the first two variables. A summary of aforementioned analysis is as follows: 1) there is a relation between some accident outcomes (i.e. "Fire/explosion", "Damage to ship or equipment", "Hull failure" and "Contact"). 2) "Navy ships" and "Fixed offshore drilling units" have different characteristics when compared with other ship types. 3 ) There is a strong relation between "Fire/explosion" and "Passenger ships". Finally, 4) there is a small relation amongst "Fishing vessels", "Flooding/Foundering" and "Loss of control".

\section{ACKNOWLEDGEMENTS}

The authors of this paper would like to acknowledge the support of the Marine Accident Investigation Branch (MAIB), who provided the required data for performing this study.

This research study was supported by EU funded H2020 SAFEMODE Project (Grant Agreement No 814961).

\section{REFERENCES}

Azadeh, A. and M. Zarrin (2016). "An intelligent framework for productivity assessment and analysis of human resource from resilience engineering, motivational factors, HSE and ergonomics perspectives." Safety Science 89: 55-71.

Chauvin, C., S. Lardjane, G. Morel, J.-P. Clostermann and B. Langard (2013). "Human and organisational factors in maritime accidents: Analysis of collisions at sea using the HFACS." Accident Analysis \& Prevention 59: 26-37.

Eliopoulou, E., A. Papanikolaou and M. Voulgarellis (2016). "Statistical analysis of ship accidents and review of safety level." Safety Science 85: 282-292.

Frangos, C. C. (2015). Proceedings of the 4th International Conference: Quantitative and Qualitative Methodologies in the Economic \& Administrative Sciences (ICQQMEAS 2015), Christos Frangos.

Kristiansen, S. (2013). Maritime Transportation: Safety Management and Risk Analysis, Taylor \& Francis.

Navas de Maya, B., R. E. Kurt and O. Turan (2018). "Application of fuzzy cognitive maps to investigate the contributors of maritime collision accidents." Transport Research Arena (TRA) 2018.

O'Hare, D., M. Wiggins, R. Batt and D. Morrison (1994). "Cognitive failure analysis for aircraft accident investigation." Ergonomics 37(11): 1855-1869.

Papanikolaou, A., K. Bitha, E. Eliopoulou, N. J. M. T. Ventikos and L. Engineering (2014). "Statistical analysis of ship accidents occurred in the period 1990-2012 and assessment of safety level of ship types."
Turan, O., R. E. Kurt, V. Arslan, S. Silvagni, M. Ducci, P. Liston, J. M. Schraagen, I. Fang and G. Papadakis (2016). "Can We Learn from Aviation: Safety Enhancements in Transport by Achieving Human Orientated Resilient Shipping Environment." Transportation Research Procedia 14: 1669-1678. 